Special Issue of the 6th International Congress \& Exhibition (APMAS2016), Maslak, Istanbul, Turkey, June 1-3, 2016

\title{
The Effect of Modification and Grain Refining on the Microstructure and Mechanical Properties of A356 Alloy
}

\author{
T. TUnÇAY* \\ Karabuk University, Technology Faculty, Department of Manufacturing Eng., 78100 Karabük, Turkey \\ In this study, microstructure and mechanical properties of modified (Al10Sr) and grain refined (Al5TiB) A356 \\ aluminum alloy were investigated. To determine the effect of modification and grain refining on the microstructure \\ and mechanical properties of A356 alloy, density measurement, optical microscope and scanning electron microscope \\ examinations and tensile tests were performed. As a result of the study, the highest density and the least percentage \\ of porosity were measured for the modified (with Al10Sr) and grain refined (with 1.5\% Al5TiB) alloy system. \\ The lowest density values and the highest percentage of porosity were measured for the unmodified and non-grain \\ refined alloy. According to the tensile tests, average ultimate tensile strength and the highest elongation were \\ obtained for the alloy modified with $\mathrm{Al} 10 \mathrm{Sr}$ and grain refined with $1.5 \% \mathrm{Al} 5 \mathrm{TiB}$ alloy. It was determined that \\ average ultimate tensile strength and percentage of elongation increased as the amount of Al5TiB added for grain \\ refinement and modified to A356 alloy increased.
}

DOI: 10.12693/APhysPolA.131.89

PACS/topics: 81.05.Bx

\section{Introduction}

A356 aluminum alloys are important alloys used in aerospace, automotive and other fields of engineering to produce parts. Modification and grain refining treatments are among treatment methods applied to achieve desired properties in these alloys [1]. The modification treatment alters the morphology of $\mathrm{Al}-\mathrm{Si}$ eutectic in the structure of alloy. With this treatment, rod-shaped (sharp-edged) silicon found in Al-Si eutectic between $\alpha$ aluminum dendrites is spherical and prevented from exhibiting notch effect under tension [2,3]. Besides, the most important advantage achieved by this treatment in A356 alloy is ductile behavior under tension. With the grain refining treatment, it is possible to reduce final grain size and improve mechanical properties. Liu et al. [4] report that pores forming around aluminum and strontium oxides when $\mathrm{Al}-\mathrm{Si}$ alloy is modified with strontium and $\beta$ Al5FeSi intermetallics nucleate around pores. The relationship between strontium and formation of pores does not only depend on amount of strontium, but also on hydrogen content of liquid aluminum. In addition, feedability of $\alpha$-Al dendrites which form around strontium reduces as well. Also, amount of hydrogen and bifilm contained by liquid metal is effective on mechanical properties and formation of pores in $\mathrm{Al}$ alloys [5]. Samuel et al. $[2,6]$ report an improvement in mechanical properties after grain refining and $\mathrm{T} 6$ heat treatment when $\mathrm{Al}-$ $\mathrm{Si}-\mathrm{Mg}$ alloy is modified with $\mathrm{Al}-10 \% \mathrm{Sr}$ at $30-200 \mathrm{ppm}$ (with $\mathrm{Al}-10 \% \mathrm{Ti}, \mathrm{Al}-5 \% \mathrm{Ti}-1 \% \mathrm{~B}, \mathrm{Al}-2.5 \% \mathrm{Ti}-2.5 \% \mathrm{~B}, \mathrm{Al}-$ $1.7 \% \mathrm{Ti}-1.4 \% \mathrm{~B}$ and $\mathrm{Al}-4 \% \mathrm{~B})[2,6]$. In addition, refining liquid metal with filtration significantly improves its mechanical properties [7]. This study investigates the effect

*e-mail: tanseltuncay@karabuk.edu.tr of modification and grain refining treatments with different amounts of $\mathrm{Al}-5 \% \mathrm{Ti}-\mathrm{B}(0-1.5 \mathrm{wt} \%)$ applied to A356 alloy on its microstructure and mechanical properties.

\section{Materials and method}

The chemical composition of master alloys used in modification and grain refining treatment applied to A356 alloy used in experimental studies is shown in Table I. The melting process was carried out with a $12 \mathrm{~kW}$ electric resistance furnace. After melting, the liquid metal was kept at $720^{\circ} \mathrm{C}$ for $5 \mathrm{~min}$ and $\mathrm{Al10Sr}(2 \mathrm{wt} \%)$ and different amounts of $\mathrm{Al} \mathrm{TiB}(0.5,1.0$, and $1.5 \%$ ) were added. Pouring temperature of all the alloys was between 730 and $745^{\circ} \mathrm{C}$. Silica sand with a grain thickness size of 60-70 AFS was used in preparation of sand molds and ester-based alkaline phenolic resin and hardener were used as binder. Casting samples of A356 alloy and runner system are shown in Fig. 1.

TABLE I

Chemical composition of A356 alloy used in the experimental study [wt\%].

\begin{tabular}{c|c|c|c|c|c|c|c|c|c}
\hline \hline & \multicolumn{10}{|c}{ Elements } \\
\cline { 2 - 9 } Alloys & $\mathrm{Si}$ & $\mathrm{Mg}$ & $\mathrm{Fe}$ & $\mathrm{Mn}$ & $\mathrm{Ti}$ & $\mathrm{Zn}$ & $\mathrm{Sr}$ & $\mathrm{B}$ & $\mathrm{Al}$ \\
\hline A356 & 7.13 & 0.375 & 0.166 & 0.001 & 0.117 & 0.005 & - & - & \\
ingot & & & 0.125 & - & - & - & 10.05 & - & bal. \\
Al10Sr & 0.048 & - & 0.12 & & - & 1.04 &
\end{tabular}

In order to remove possible inclusions occurring during the casting process from casting samples, 20 ppi ceramic foam filters $\left(25 \times 25 \times 15 \mathrm{~mm}^{3}\right)$ were used in the runner system. 12 tensile test samples were prepared for each alloy group in accordance with ASTM: B557M-10. A356 alloy casting samples, which were applied with different grain refining treatments, were kept in solution at $540{ }^{\circ} \mathrm{C}$ for $8 \mathrm{~h}$ and then quenched in water. The samples 


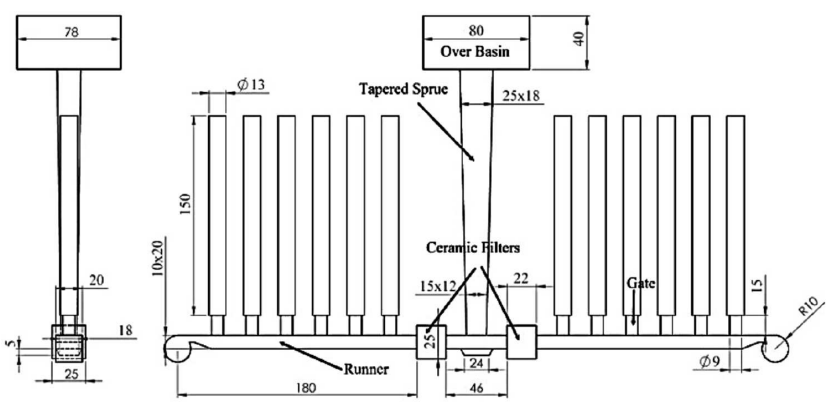

Fig. 1. Schematic view of casting samples of A356 and runner system.

were naturally aged at room temperature for $24 \mathrm{~h}$ and artificially aged at $170^{\circ} \mathrm{C}$ for $10 \mathrm{~h}$ (T6). Metallographic samples were prepared for microstructural examinations in accordance with metallographic preparation standard (ASTM E04.01). The prepared samples were etched with Keller's reactive $(2 \mathrm{ml} \mathrm{HF}(48 \%)+3 \mathrm{ml} \mathrm{HCl}+5 \mathrm{ml}$ $\mathrm{HNO}_{3}+190 \mathrm{ml} \mathrm{H}$ O) for $30 \mathrm{~s}$. Optical microscope (OM) examinations and secondary dendrite arm spacing (SDAS) measurements were performed with a MEIJI optical microscope and image analysis was performed with an MSQ PLUS 6.5. Scanning electron microscope (SEM) examinations were performed with a Carl Zeiss Ultra Plus Gemini (FEG) scanning electron microscope. Rigaku Ultima IV X-ray diffractometer (XRD) was used to identify phases. Tensile testing was performed using a SHIMADZU AG-IS tensile test device with a capacity of $50 \mathrm{kN}$ at $1 \mathrm{~mm} / \mathrm{min}$ tensile speed.

\section{Microstructure and tensile testing results}

$\mathrm{OM}$ and SEM images of unmodified and modified A356 alloys depending on Al5TiB content are shown in Fig. 2a,d and e. $\alpha$-Al dendrites and $\mathrm{Al}-\mathrm{Si}$ eutectic formed in structure are seen in $\mathrm{OM}$ images and iron-based intermetallic compounds are seen in SEM images (Fig. 2c and Fig. 3a) and XRD (Fig. 3b) analyses. Also, porosities form between dendrites due to shrinkages (macro and micro) and oxide film content. It is clearly seen that sharpedged $\mathrm{Si}$ in $\alpha$-Al dendrites and $\mathrm{Al}-\mathrm{Si}$ eutectic forming between dendrites are refined and spherical with strontium modification (Fig. 2b). The ceramic foam filters used in the runner system increase liquid metal quality and improve mechanical properties $[8,9]$.

Formation of porosity during solidification of liquid metal is associated with oxide film content of liquid metal, the runner system and hydrogen dissolved in liquid metal $[5,9,10]$. SEM mapping image of A356 modified with Al10Sr and grain refined with $1.5 \%$ Al5TiB is shown in Fig. 3a. Fracture surface of samples are seen in certain parts of coarse grained Al-Si eutectic and iron-based intermetallics seem to form around Al-Si eutectic [6].

For experimental studies, unmodified A356 alloy and A356 alloys modified in 200-250 ppm range and grain refined with different amounts of $\mathrm{Al} 5 \mathrm{TiB}$ were produced. XRD analysis results of unmodified A356 alloy and A356 alloy modified with Al10Sr and grain refined with $1.5 \%$
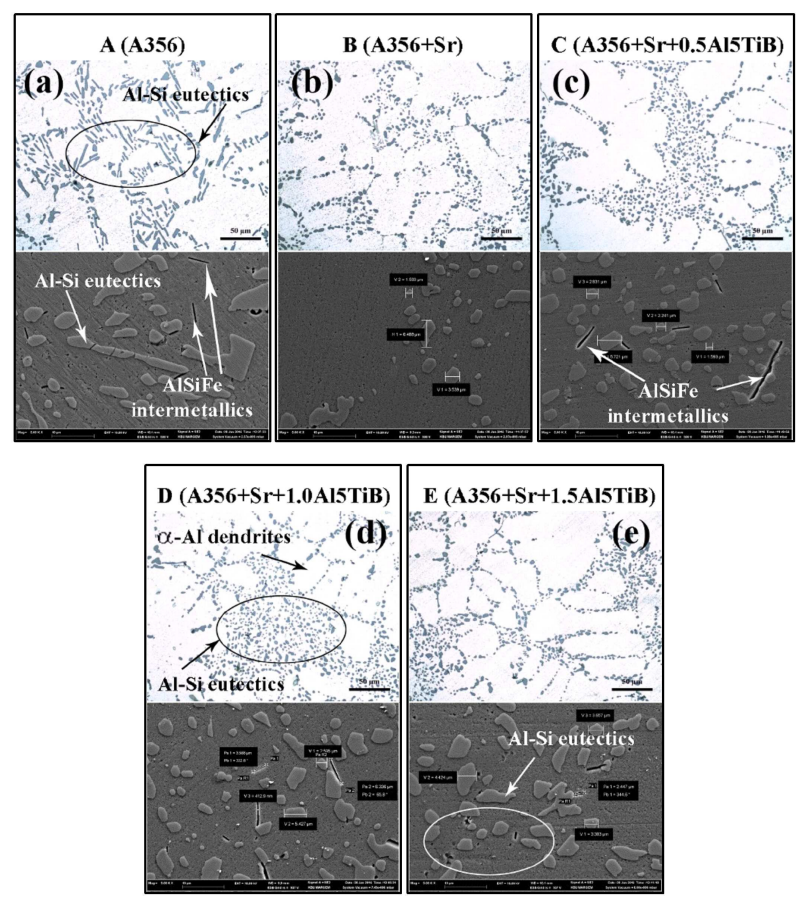

Fig. 2. OM and SEM images of unmodified and modified A356 alloys, A356 (a), A356+Sr (b), $\mathrm{A} 356+\mathrm{Sr}+0.5 \mathrm{Al} 5 \mathrm{TiB}(\mathrm{c}), \mathrm{A} 356+\mathrm{Sr}+1.0 \mathrm{Al} 5 \mathrm{TiB}(\mathrm{d})$ and $\mathrm{A} 356+\mathrm{Sr}+1.5 \mathrm{Al} 5 \mathrm{TiB}(\mathrm{e})$.

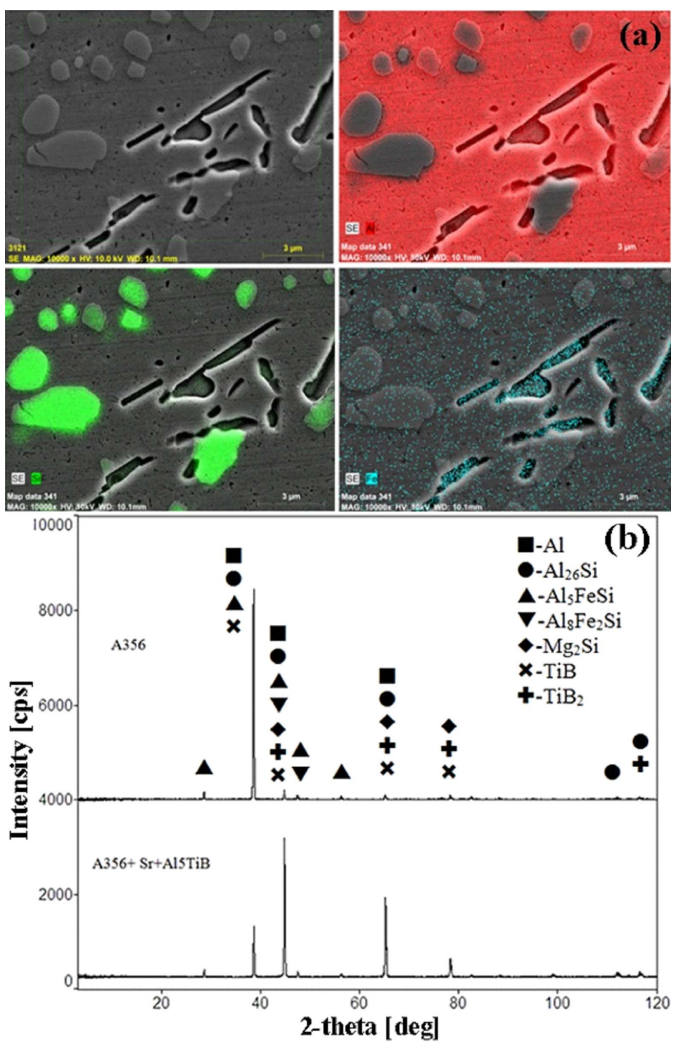

Fig. 3. SEM mapping images of $\mathrm{A} 356+\mathrm{Sr}+1.5 \mathrm{Al} 5 \mathrm{TiB}$ (a) and $\mathrm{XRD}$ (b) of unmodified A356 and A356+Sr+1.5Al5TiB. 
Al5TiB are shown in Fig. 3b. After the solidification, it was found that $\alpha$ - $\mathrm{Al}$ dendrites $\mathrm{Al}-\mathrm{Si}$ eutectic $\left(\mathrm{Al}_{26} \mathrm{Si}\right.$ sharp-edged), monoclinic $\beta-\mathrm{Al}_{5} \mathrm{FeSi}$ (needle shaped stratified structure), hexagonal $\alpha-\mathrm{Al}_{8} \mathrm{Fe}_{2} \mathrm{Si}$ (Chine script structure) and $\delta$ - $\mathrm{Al}_{4} \mathrm{FeSi}_{2}$ intermetallic phases formed in structure of A356 alloy depending on amount of iron in the compound and solidification conditions. In addition, $\mathrm{TiB}$ and $\mathrm{TiB}_{2}$ phases were identified in Al5TiB master alloy after modification and grain refining treatments. Especially 39, 44, 65 and 78 degrees of $2 \Theta$ angle showed transformed phases in structure. Image analysis results, SDAS, percentage of porosity (PA \%), average ultimate tensile strength (Av. UTS), and percentage of elongation (Av. e \%) results are given in Table II. According to SDAS results given in Table II, SDAS decreases as the amount of Al5TiB master alloy added for grain refining increases. This is because $\mathrm{TiB}_{2}$, $\mathrm{TiB}$ and $\mathrm{Al}_{3}$ Ti intermetallics added to structure with dissolution of Al5TiB alloy allow heterogeneous nucleation during solidification. This change affects the morphology of iron-based intermetallics as well. In a previous study, morphology of silicon particles was reported to change in parallel with the increase in casting temperature in modified and unmodified alloys $[6,10]$.

TABLE II

Tensile testing and image analysis results of A356 alloys.

\begin{tabular}{c|c|c|c|c}
\hline \hline Designation & $\begin{array}{c}\text { Av. UTS } \\
{[\mathrm{MPa}]}\end{array}$ & Av. e [\%] & SDAS [ $\mu \mathrm{m}]$ & PA [\%] \\
\hline A & 174 & 8.71 & 26.8 & 4.81 \\
B & 182 & 8.2 & 27.7 & 4.79 \\
C & 210 & 8.48 & 22.5 & 4.04 \\
D & 216 & 8.09 & 21.6 & 3.50 \\
E & 229 & 9.21 & 19.6 & 3.14
\end{tabular}

A clear increase in ultimate tensile strength and percentage of elongation value is seen with the addition of Al5TiB master alloy. Average ultimate tensile strength increased by $4 \%$ with modification, whereas after grain refining treatment average ultimate tensile strength increased by $15 \%$ (C), $18 \%$ (D) and $25 \%$ (E), respectively. However, a clear relationship was not observed in average percentage of elongation values obtained in different tensile tests. Percentage of porosity in A356 alloys decreases with modification and grain refining. Mechanical properties of A356 alloys improve with strontium modification.

\section{Conclusion}

Microstructure and mechanical properties of A356 casting alloy modified with Al10Sr and grain refined with different amounts of Al5TiB master alloy were investigated and the following results are obtained:

- It was found that sharp-edged morphology of Al-Si eutectic tended to be spherical with $\mathrm{Sr}$ addition to A356 alloy.

- It was observed that SDAS decreased in A356 alloy with modification and with increasing amount of Al5TiB master alloy, whereas porosity on surfaces of metallographic samples decreased.

- According to the results of tensile testing, the increase in amount of Al5TiB master alloy (grain refining treatment) resulted in an increase in ultimate tensile strength.

- Depending on grain refining rate of A356 alloy, dimensions of silicon eutectic and iron-based intermetallics decrease and its morphology changes.

\section{References}

[1] W.S. Miller, L. Zhuang, J. Bottema, A.J. Wittebrood, P. De Smet, A. Haszler, A. Vieregge, Mater. Sci. Eng. A 280, 37 (2000).

[2] A.M. Samuel, H.W. Doty, S. Valtierra, F.H. Samuel, 0.1016/j.matdes.2013.10.029Mater. Des. 56, 264 (2014).

[3] E. Wang, T. Gao, J. Nie, X. Liu, J. Alloys Comp. 594, 7 (2014).

[4] L. Liu, A.M. Samuel, H.H. Samuel, H.W. Doty, S. Valtierra, J. Mater. Sci. 38, 1255 (2003).

[5] D. Dispinar, J. Campbell, Mater. Sci. Eng. A 528, 3860 (2011)

[6] E. Samuel, B. Golbahar, A.M. Samuel, H.W. Doty, S. Valtierra, F.H. Samuel, Mater. Des. 56, 468 (2014)

[7] T. Tunçay, D. Özyürek, J. Fac. Eng. Archit. Gaz. 29, 271 (2014).

[8] T. Tunçay, S. Tekeli, D. Özyürek, J. Fac. Eng. Archit. Gaz. 28, 241 (2013).

[9] G. Eisaabadi B., P. Davami, S.K. Kim, M. Tiryakioğlu, Mater. Sci. Eng. A 579, 64 (2013).

[10] S. Joseph, S. Kumar, Mater. Sci. Eng. A 588, 111 (2013). 